\title{
Informed consent for medical photographs
}

\author{
Dysmorphology Subcommittee of the Clinical Practice Committee, American College of Medical Genetics
}

\begin{abstract}
Patient images are used for many purposes in medical practice. They are placed in the medical record as an adjunct to clinical care, displayed to colleagues, students and other audiences in educational settings, and published in medical journals or other media as part of medical research. In each case it is not only prudent, but necessary for the patients' protection and interest that appropriate consent be obtained. While medical journals invariably require written consent for photographs that may identify the patient, the format of the photograph consent form is usually not specified, nor is it always clear which images require consent. With the proliferation of published images on the Internet it has become particularly important to obtain permission for all uses that will be made of medical images, including worldwide distribution through various electronic media.

There is general agreement that patient images require the same consent and confidentiality safeguards that pertain to other parts of the medical record, even when not used in publication. Historically, the focus of clinicians and medical journals has been to preserve the anonymity of their patients and subjects. Over the past decade, however, this focus has shifted toward obtaining full consent for all images, even those that do not identify the patient. ${ }^{1}$ Many authors and editors, including the International Committee of Medical Journal Editors, ${ }^{2}$ now agree on a policy of full consent for most images. Many journals have outlined new procedures for obtaining patient consent for publication of medical images, including the British Medical Journal, ${ }^{3}$ which has also drafted a sample consent form that is available on their website. ${ }^{4}$ In this policy statement, we examine the key elements of consent for medical photographs, suggest those items that should be included in the consent form, and offer a sample form that can be adapted for use in a variety of settings (Fig. 1).

Patient photographs are an especially important part of the medical record in clinical genetics units. Such images can aid in the diagnostic process both through documentation of a changing phenotype with age and to obtain expert opinion from other practitioners who have more experience with a diagnosis that is being considered but has not been confirmed.
\end{abstract}

The long-term follow-up of patients with undiagnosed disorders may eventually yield diagnoses that are not apparent from only one or two evaluations; patient photographs may be helpful in this diagnostic process. Photographs are also essential for medical teaching. They may be used to illustrate the characteristic phenotypic features when syndrome recognition is being taught to an audience, and they provide an important "gestalt" that a verbal or written description cannot provide. Finally, in the research setting, when a new syndrome is described or when the clinical spectrum of an already-described disorder is further delineated, medical photographs are critical pieces of information that form the basis for phenotype recognition by other clinicians. Patient images are also used in research on the natural history of genetic disorders by providing longitudinal information about the changing phenotype.

To examine the issues to be considered in consenting for photographs, we ask the basic questions of who, what, and where? Who can or should be able to provide consent? What are the uses to which the photograph will be put? Where will the photograph be displayed? The answers to these questions must be given within the framework of the dual principles of consent and confidentiality. It is universally accepted that patients must give consent to publication whenever there is a possibility that the patient will be identified. ${ }^{25,6}$ While some journalistic policies do not require patient consent for nonidentifying information, ${ }^{2}$ there is disagreement on this point. ${ }^{3}$ As a matter of course, we suggest that all published clinical photographs, whether likely or not to be identifying, should have appropriate consent from the patient.

In general, the person whose photograph is being taken should be the one to provide consent, much as consent for treatment is given by the patient to whom the treatment is being offered. However, consent may be given by parents or guardians for photographs of minors or those who are developmentally disabled. Because these populations are strongly represented in clinical genetics publications, a specific policy is needed to govern the consent process for these individuals. There have been a number of investigations regarding the abil-

\footnotetext{
This guideline is designed primarily as an educational resource for medical geneticists and other health care providers to help them provide quality medical genetic services. Adherence to this guideline does not necessarily ensure a successful medical outcome. This guideline should not be considered inclusive of all proper procedures and tests or exclusive of other procedures and tests that are reasonably directed toward obtaining the same results. In determining the propriety of any specific procedure or test, the geneticist should apply his or her own professional judgment to the specific clinical circumstances presented by the individual patient or specimen. It may be prudent, however, to document in the patient's record the rationale for any significant deviation from this guideline.
} 


\section{Patient Consent for Medical Photography}

Patient name:

Date:

check here if minor or unable to provide consent

I consent for medical photographs to be made of me or my child (or person for whom I am legal guardian). I understand that the information may be used in my medical record, for purposes of medical teaching, or for publication in medical textbooks or journals as I have designated below. By consenting to these medical photographs I understand that I will not receive payment from any party. Refusal to consent to photographs will in no way affect the medical care I will receive. If I have any questions or wish to withdraw my consent in the future I may contact:

By signing this form below I confirm that this consent form has been explained to me in terms which I understand.

1) I consent for these photographs to be used in medical publications, including medical journals, textbooks, and electronic publications. I understand that the image may be seen by members of the general public, in addition to scientists and medical researchers that regularly use these publications in their professional education. Although these photographs will be used without identifying information such as my name, I understand that it is possible that someone may recognize me. I also agree for my image to be shown for teaching purposes and to be used for my medical record.

(Signature)

(Witness)

2) I agree for my image to be shown for teaching purposes AND to be used for my medical record but NOT FOR medical publication:

(Signature)

(Witness)

3) I agree to use of my image for medical records ONLY:

(Signature)

(Witness)

For patients between ages 7 and 18 years, a signature below indicates that the information in this consent form has been explained to me, and I assent to use of my images as outlined above:

(Signature of patient)

(Witness) 
ity of children to consent to treatments or other special procedures. ${ }^{7,8}$ Parental consent is generally not necessary for patients who are 18 years of age or older. Based on recommendations of the National Commission for the Protection of Human Subjects of Biomedical and Behavioral Research, regulations regarding informed consent for research have been formulated for children between age 7 and 18 years. ${ }^{9}$ These regulations state that research involving children 7 years and older should obtain legal permission from a parent or guardian as well as assent from the child. Some patients with developmental disabilities will not be able to provide informed consent. The criteria for this population are not well delineated, but should logically be treated in much the same way as that used for children. That is, the parent or guardian should be asked to provide informed permission for the images to be taken, and whenever possible, assent of the patient should also be sought. For those patients unable to provide assent, parents or guardians can provide consent, much as they would for a young child. In general, it can be assumed that parent or guardian consent is necessary for all persons who do not have the ability to provide either consent or assent. In addition to those who are developmentally disabled or below the age of assent, this would also include special situations such as fetal death and stillbirth.

Patients will need to provide consent for all uses that will be made of the image. There will rarely be an issue with photographs that are being used exclusively within the medical record, but use for medical teaching or medical publication may not be so readily accepted. Because of this, our model consent form allows signatories to agree to use for any or all of these purposes. The photographer should discuss explicitly all the uses of the image, especially including its use in electronic publications that may reach a wider audience than standard medical texts and journals. It should also be emphasized that the image will be placed in the public domain and cannot be removed once it has been published. It is often helpful to show the patient the image that will be used beforehand so that they can see what will actually appear in print. Although there is concern that the procedures we propose may result in a decrease in patient material available for publication, investigators have found that the great majority of patients continue to consent for publication of the image despite specific discussion of the potential availability of the image on the Internet. ${ }^{3,10} \mathrm{We}$ recommend that a copy of the consent form be given to the patient and that the form include a contact number that can be used in the future, should the patient or family wish to withdraw their consent. If at any time the patient or the patient's parent or guardian wishes to withdraw consent, the image should be removed from display in whatever format it appears. While it will be possible to remove the image easily from an Internet site, from a clinician's teaching file, or from a medical record, it should be recognized that print media images cannot be retracted, nor can the clinician be responsible for further use of the image by someone who has downloaded it from an Internet site. It is important for patient reassurance that the consent form explicitly state that the patient's medical care will not be affected in any way by their refusal to consent to photography nor by their request to remove an image from any of its uses.

We provide a model consent form in the hope that it will be adopted by geneticists and other medical researchers to ensure fully informed consent for all their patient populations. This issue is not only important for medical publications but also for individuals who use patient images for teaching and for providing phenotypic documentation in the patient medical record. Geneticists and genetic counselors have deep respect for patient autonomy and have made it a cornerstone of the care they provide. Autonomy to provide consent and to maintain confidentiality of medical information will further empower our patients to exercise control over their medical care and to take full responsibility for their informed medical decisions.

Approved by the American College of Medical Genetics Board of Directors on July 8, 2000.

(C) AMERICAN COLLEGE OF MEDICAL GENETICS, 2000

9650 Rockville Pike, Bethesda, MD 20814-3998

Phone 301-530-7127, Fax 301-571-1895

Dysmorphology Subcommittee of the Clinical Practice Committee, American College of Medical Genetics Christopher Cunniff, MD

Janice L.B. Byrne, MD

Louanne M. Hudgins, MD

John B. Moeschler, MD

Ann Haskins Olney, MD

Richard M. Pauli, MD, PhD

Lauri H. Seaver, $M D$

Cathy A. Stevens, MD

Christopher Figone, Consumer Representative

\section{References}

1. Smith R. Informed consent: edging forwards (and backwards). BMJ 1998:316:949951.

2. International Committee of Medical Journal Editors. Protection of patients' rights to privacy. BMJ 1995;311:1272.

3. Hood CA, Hope T, Dove P. Videos, photographs, and patient consent. BMJ 1998; 316:1009-1011.

4. British Medical Journal,1998 http://www.bmj.com

5. Smith R. Publishing information about patients. BMJ 1995;311:1240-1241.

6. Smith R. Commentary. The importance of patients' consent for publication. BMJ 1996;313:16

7. Susman EJ, Dorn LD, Fletcher IC. Participation in biomedical research: the consent process as viewed by children, adolescents, young adults, and physicians. J Pediatr 1992;121:547-552

8. American Academy of Pediatrics Committee on Bioethics. Informed consent, parental permission, and assent in pediatric practice. Pediatrics 1995;95:314-317.

9. U.S. Department of Health and Human Services. 45 Code of Federal Regulations 46 Subpart D - Additional protection for children involved as subjects in research. Federal Register March 8, 1983;48:9818.

10. Nicholl D, Davies D. Videos, photographs, and patient consent: most patients agree to be videoed for teaching and publication purposes [letter]. BMJ 1998:317:1523 